\title{
The effects of oral protein on the absorption of intraduodenal levodopa and motor performance
}

\author{
J P FRANKEL, * P A KEMPSTER, * M BOVINGDON, $\uparrow$ R WEBSTER, $\uparrow$ A J LEES, * \\ G M STERN*
}

From the Department of Neurology,* The Middlesex and University College Hospitals School of Medicine and Department of Pharmacology, $†$ University College, London, UK

SUMMARY Four patients with levodopa induced fluctuations in motor performance were studied during the constant intraduodenal infusion of levodopa. The results confirm that steady plasma levodopa levels with stable motor control can be achieved. However, when patients were given oral protein loads, motor performance declined despite maintenance of plasma levodopa levels. These findings suggest that competition for levodopa carrier mediated transport by amino acids, is more important at the blood-brain barrier than across the gut mucosa; thereby possibly limiting the efficacy of long-term direct intraduodenal administration of levodopa.

Fluctuation of motor function is usual in levodopa treated patients with Parkinson's disease.' The peripheral pharmacokinetic properties of levodopa lead to variable delivery to the central nervous system and contribute to motor oscillations. These include effects of gastrointestinal factors influencing absorption, ${ }^{2}$ relatively rapid peripheral metabolism of levodopa and competition for active transport across the blood-brain barrier. ${ }^{34}$

Patients taking oral levodopa frequently remark that after a large protein-containing meal their medication fails to work. Cotzias was able to confirm this observation and advocated a low protein diet. ${ }^{5}$ Delayed or erratic gastric emptying and competition between levodopa and large neutral amino acids for gut mucosal carrier systems may impair levodopa absorption. ${ }^{6}$ However, motor function is also adversely affected by oral amino acid intake when stable plasma levodopa levels are maintained by intravenous infusion, ${ }^{7}$ suggesting that competition for transport across the blood-brain barrier also occurs. This has also been demonstrated by in vivo positron emission tomographic (PET) imaging. ${ }^{8}$ In practice the importance of this factor in patients receiving conventional oral levodopa medication is difficult to determine, as plasma levodopa and amino acid levels may be simultaneously affected by the ingestion of protein-rich food.

Address for reprint requests: Dr A J Lees, Department of Neurology, The Middlesex Hospital, London WIN 8AA, UK.

Received 14 February 1989.

Accepted 22 March 1989
Continuous infusion of levodopa by naso-duodenal tube leads to more stable plasma levels and overall improvement of motor performance. ${ }^{910}$ By achieving constant delivery of levodopa to intestinal absorption sites, the effects of protein intake on the pharmacokinetics of levodopa absorption and its access to the central nervous system may be more readily examined.

We have studied the effects of protein ingestion in four Parkinsonian patients receiving intra-duodenal infusions of levodopa. In an attempt to clarify the problem, the relative influence of competition for transport across the gut mucosa and the blood-brain barrier were compared by examining the relationship between motor function and the plasma levels of levodopa and large neutral amino acids.

\section{Patients and methods}

Four patients (two male and two female) with idiopathic Parkinson's disease were studied. Their mean age was 65 years (59-73), duration of disease 10 years (8-15) and duration of levodopa therapy $9 \cdot 3$ years (7-15). All four had developed fluctuations of motor functions in relation to doses of levodopa, which in two cases were severe. Informed consent was obtained from all patients.

A naso-duodenal tube was passed under fluoroscopic control on the day prior to study. The patients were fasted and usual antiparkinsonian medication withheld overnight. Benserazide was given by mouth before the study and at regular intervals thereafter. Levodopa solution $(5 \mathrm{mg} / \mathrm{ml})$ was given via the naso-duodenal tube starting with a $50 \mathrm{mg}$ bolus and followed by a continuous infusion at a rate of $50 \mathrm{mg}$ per hour. The infusion rate was adjusted according to the motor response. After four hours, when the patients 
showed stable motor improvement, a high protein drink was given. Following study of the first patient (fig 1) the protocol was modified; the remaining three patients received a larger loading dose of benserazide (100 mg vs $50 \mathrm{mg})$, the interval between subsequent doses was reduced from 6 to 4 hourly and a single oral protein load of 60 grams was given.

Motor performance was assessed at 30 minute intervals by measuring; alternate unilateral hand tapping (for 30 seconds) on digital counters mounted $20 \mathrm{~cm}$ apart; timed walking over a 12 metre distance and clinical assessments of tremor and dyskinesias according to simple four point scales (0-nil, 1-mild, 2-moderate, 3-severe, 4-incapacitating).

Blood for levodopa and 3-0-methyldopa assays was taken before the infusion and immediately before each motor evaluation. Plasma samples were stored at $-70^{\circ} \mathrm{C}$. Aliquots $(500 \mu \mathrm{l})$ were treated with $60 \%$ perchloric acid $(20 \mu \mathrm{l})$ to precipitate protein and $20 \mu \mathrm{l}$ samples of clear supernatant were analysed by HPLC. This consisted of an MSI 660 Autosampler (at $+5^{\circ} \mathrm{C}$ ) and a 420 pump (Kontro, UK) with an LCA-15 Electrochemical detector (EDT, UK) at 0.70V

Patient 1
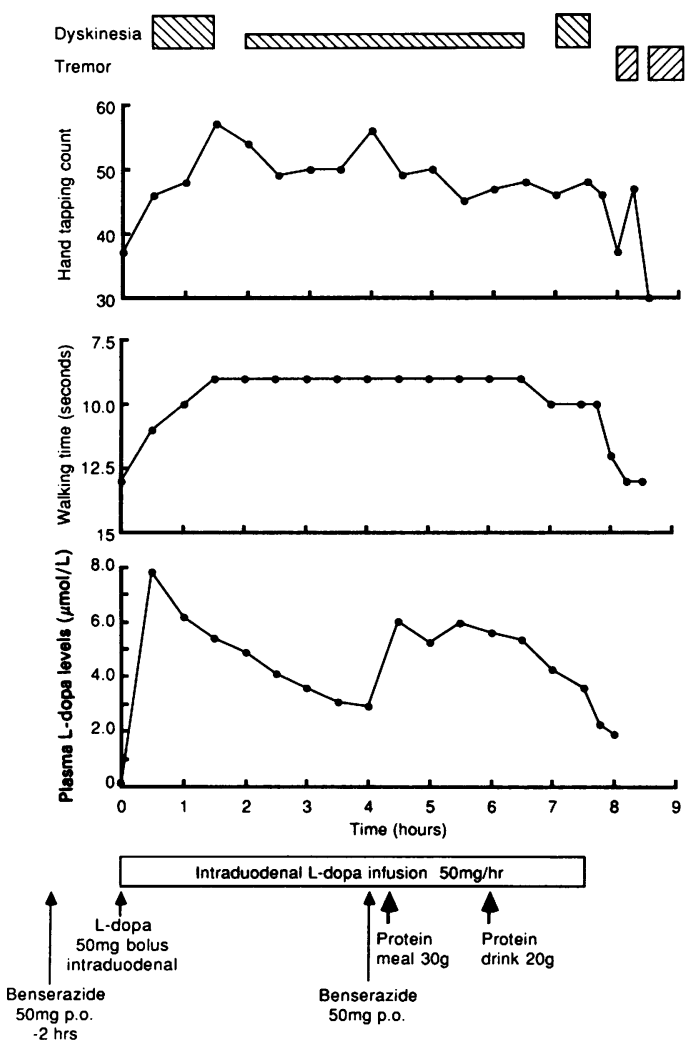

Fig 1 Patient 1. Stable improvement in motor performance is maintained throughout the period of intraduodenal infusion. Plasma levodopa levels are seen to vary in relation to the timing of benserazide doses. Protein ingestion has no effect on motor performance or plasma levodopa levels. oxidation potential, and a Shimadzu CR1B integrator. Isocratic elution was carried out at $1.0 \mathrm{ml} /$ minute at $20^{\circ} \mathrm{C}$ on a $15 \mathrm{~cm}$ SSODS- 2 column (HPLC Technology UK). The mobile phase contained citric acid $(12.60 \mathrm{~g} / \mathrm{l})$, sodium dihydrogen orthophosphate $(5.68 \mathrm{~g} / 1)$, heptanesulfonic acid sodium $(0.202 \mathrm{~g} / \mathrm{l})$ disodium EDTA $(0.100 \mathrm{~g} / \mathrm{l})$ and acetonitrile $(20 \mathrm{ml} / \mathrm{l})$ in deionised water, finally adjusted to $\mathrm{pH} 2.5$ with hydrochloric acid, and degassed on-line. Inter-assay variability for levodopa concentration was $7 \cdot 1 \%$.

Plasma samples taken before and after the liquid protein meal were also assayed for the large neutral amino acids isoleucine, leucine, phenylalanine, tryptophen, tyrosine and valine by an HPLC procedure based on pre-column derivatization with $\mathrm{O}$-phthaldehyde and fluorescence detection."

\section{Results}

Correlation between motor function and plasma levodopa concentration in cases $1,2 \& 4$ are shown in figs 1-3 and biochemical results for all patients are summarised in the table.
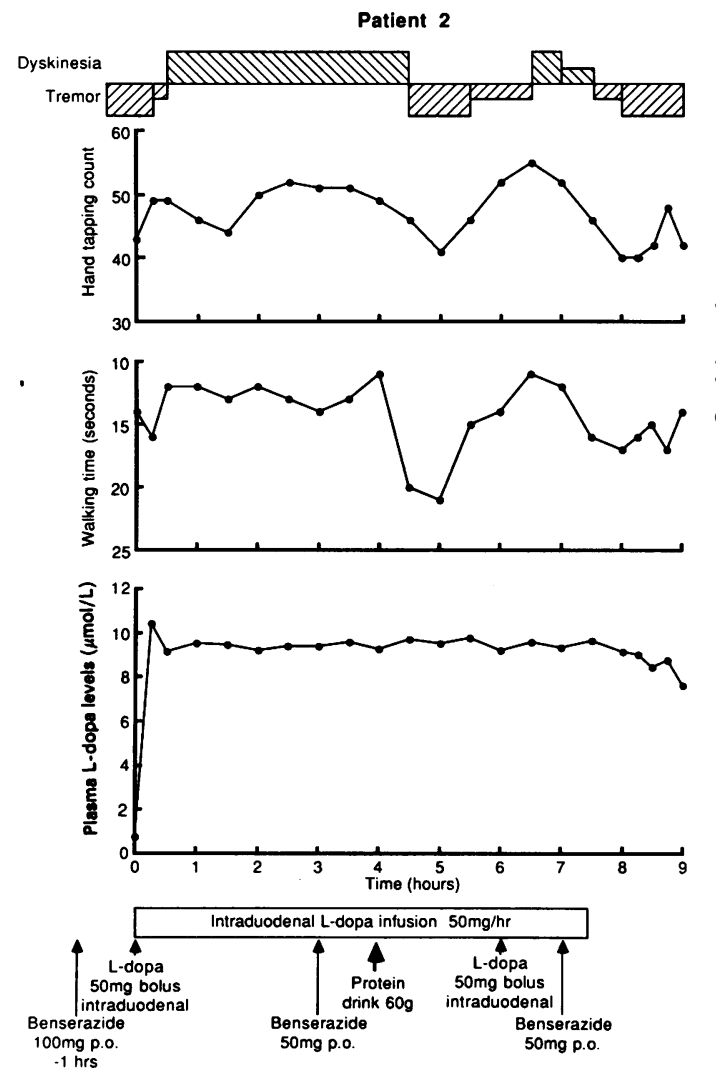

Fig 2 Patient 2. Both stable motor performance and plasma levodopa levels are produced for the first four hours of the study. Following the oral protein load motor function deteriorates abruptly despite maintenance of preprandial plasma levodopa values. 
Table Biochemical results and motor scoring for all patients before and after protein loading

\begin{tabular}{|c|c|c|c|c|c|c|c|c|c|c|}
\hline \multirow[b]{2}{*}{ Patient } & \multicolumn{2}{|c|}{$\begin{array}{l}\text { Levodopa levels } \\
\text { (umol/l) }\end{array}$} & \multicolumn{2}{|c|}{$\begin{array}{l}\text { 3-O-Methyl dopa levels } \\
(\text { (umol/l) }\end{array}$} & \multicolumn{2}{|c|}{$\begin{array}{l}\text { Large neutral amino } \\
\text { acid levels (umol/l) }\end{array}$} & \multicolumn{2}{|c|}{$\begin{array}{l}\text { Tapping } \\
\text { (Taps } / 30 \text { seconds) }\end{array}$} & \multicolumn{2}{|c|}{$\begin{array}{l}\text { Walking } \\
\text { (Seconds) }\end{array}$} \\
\hline & Before & After & Before & After & Before & After & Before & After & Before & After \\
\hline $\begin{array}{l}1 \\
2 \\
3 \\
4\end{array}$ & $\begin{array}{l}3 \cdot 27 \\
9 \cdot 41 \\
8 \cdot 35 \\
6 \cdot 54\end{array}$ & $\begin{array}{l}6 \cdot 04 \\
9 \cdot 55 \\
8 \cdot 47 \\
7 \cdot 79\end{array}$ & $\begin{array}{l}17 \cdot 02 \\
33 \cdot 5 \\
27 \cdot 54 \\
31 \cdot 2\end{array}$ & $\begin{array}{l}24 \cdot 22 \\
35 \cdot 7 \\
32.02 \\
33 \cdot 5\end{array}$ & $\begin{array}{r}1411 \\
879 \\
1183 \\
956\end{array}$ & $\begin{array}{l}1625 \\
1962 \\
2292 \\
1776\end{array}$ & $\begin{array}{l}50 \\
51 \\
59 \\
61\end{array}$ & $\begin{array}{l}49 \\
41 \\
46 \\
21\end{array}$ & $\begin{array}{c}9 \\
13 \\
10 \cdot 5 \\
8\end{array}$ & $\begin{array}{r}9 \\
21 \\
11 \\
15\end{array}$ \\
\hline
\end{tabular}

In all four patients it was possible to produce a sustained "on" state with continuous intraduodenal infusion of levodopa (range $50-70 \mathrm{mg} /$ hour) in the fasting state. In Cases 2, 3\& 4, plasma levodopa levels remained relatively stable with a mean preprandial concentration of $8.1 \mu \mathrm{mol} / 1$ (see table). In case 1 , a lower initial dose of benserazide was associated with
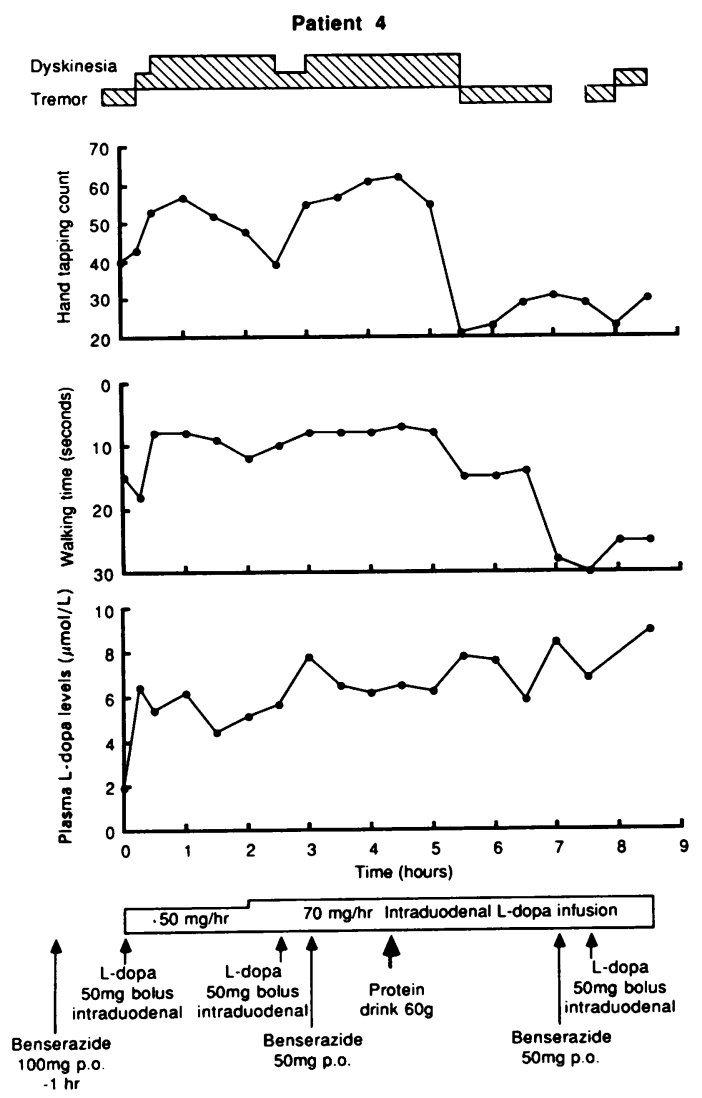

Fig 3 Patient 4. Stable motor control in this patient required the levodopa infusion rate to be increased from $50 \mathrm{mg} /$ hour to $70 \mathrm{mg} /$ hour. Again reversal of motor benefit occurs on levodopa, despite maintained plasma levels, after protein ingestion. progressive decay of plasma levodopa concentration although motor response was not affected. The mean fasting large neutral amino acid levels were $1006 \mu \mathrm{mol} / \mathrm{l}$ and mean fasting plasma 3-0-methyldopa was $30.7 \mu \mathrm{mol} / 1$.

A decline in motor function was observed in cases 2 , $3 \& 4$ following protein administration although the mean post-prandial levodopa level was in fact slightly increased at $8.6 \mu \mathrm{mol} / 1$. In these cases, the postprandial large neutral amino acid level had risen to a mean value of $2010 \mu \mathrm{mol} / 1$, an average increase of $\mathbf{9 9 . 8} \%$. Mean post-prandial 3-0-methyldopa concentration was relatively unchanged at $33.7 \mu \mathrm{mol} / 1$.

Post-prandial levodopa concentration in case 1 continued to show fluctuations, in relation to timing of benserazide doses, but motor function did not decline until the intraduodenal infusion was stopped at the end of the study. In this patient, post-prandial large neutral amino acid levels rose to $1625 \mu \mathrm{mol} / 1$ an increase of $15 \cdot 2 \%$.

\section{Discussion}

Intraduodenal infusion of levodopa produced steady plasma levels in three out of four patients with motor fluctuations, which in the fasting state were accompanied by stable motor control. Following administration of an oral protein load in these three patients there was an increase in plasma large neutral amino acid levels, with impairment of motor function but no significant change in plasma levodopa. That these effects were not observed in case 1 is probably explained by the variations in the protocol. Fluctuation of plasma levodopa occurred in both fasting and post-prandial phases in this patient and correlated closely with oral benserazide doses, suggesting that peripheral aromatic amino acid decarboxylase inhibition was incomplete. The administration of a lower protein load caused a smaller rise in neutral amino acid levels which did not adversely affect motor response to levodopa.

Animal studies have shown that a common active transport mechanism exists for the absorption of levodopa and large neutral amino acids across the intestinal mucosa. This carrier system is saturable and 
in vitro experiments demonstrate that competition with large neutral amino acids can impair levodopa transport. $^{12}$ Similar saturable carrier mediated transport of levodopa occurs across the blood-brain barrier. ${ }^{3}$ In patients on conventional oral levodopa/ peripheral decarboxylase inhibitor medication, changes in gastric and small bowel motility also contribute to the impairment of levodopa absorption which is seen in relation to ingestion of meals. ${ }^{13} \mathrm{By}$ ensuring constant and reliable delivery of levodopa to the small bowel, the present study in effect compares the relative influence of competition between levodopa and large neutral amino acids at both intestinal mucosal and blood-brain barrier sites. Ingestion of a high protein drink was found to reverse the motor response to intraduodenal infusion without altering plasma levodopa values when plasma levels of large neutral amino acids had doubled from fasting values. This indicates that the adverse effects of protein loading upon motor function are chiefly due to antagonism of passage of levodopa across the bloodbrain barrier rather than across the gut mucosa. The observation that motor performance varies in relation to plasma large neutral amino acid levels is in agreement with several previous studies. ${ }^{14} 15$

Several possible explanations can be advanced as to why protein apparently impaired the entry of levodopa into the central nervous system without affecting its absorption from the gut. The ratio of the molar concentration of large neutral amino acids to levodopa in the fasting state was approximately 100:1, increasing to over 200:1 after protein loading. In the intestinal lumen, the concentration of levodopa may have been higher relative to free neutral amino acids at the sites where levodopa is actively absorbed, lessening the effect of competition for transport. Alternatively, large neutral amino acid transport sites may be more densely distributed on the intestinal mucosa than on the blood-brain barrier. It has previously been suggested that accumulation of 3-0-methyldopa, a major metabolite of levodopa may also compete for transport across the blood-brain barrier ${ }^{16}$ and thus affect motor function. Our findings show that the plasma 3-0-methyldopa concentration represents only a small fraction of the blood large neutral amino acids which are in competition with levodopa for active transport. Assuming that all large neutral amino acid species have similar affinities for active transport sites, it seems unlikely that 3-0-methyldopa would exert any significant influence on motor response to levodopa by this mechanism.

By emphasising the importance of antagonism of levodopa transport across the blood-brain barrier, our findings are likely to be relevant to the use of techniques designed to produce more constant delivery of levodopa to gastrointestinal absorption sites. Naso-duodenal infusions can lead to sustained overall improvement in Parkinsonian motor disability. Furthermore, it has been suggested that the effectiveness of enteral administration may be improved by the creation of isolated intestinal pouches. ${ }^{17}$ However, as the principal influences of protein loading appear to be mediated at the bloodbrain barrier, neither technique is likely to completely ameliorate the effects of diet. These problems will also limit the potential efficacy of slow-release formulations of levodopa which would at best produce plasma profiles inferior to continuous delivery systems.

The authors thank the departments of Radiology, Medical Illustration and Photography at the Middlesex Hospital, London for their help with this study and Dr F Zia-Gharib from the department of Pharmacology, University College, London for performing the amino acid assays.

The HPLC analysis of levodopa and 3-0-methyl dopa were made possible by a grant from the Parkinson's Disease Society.

PAK and JPF were supported by the Kate Stillman Research Fellowship.

\section{References}

1 Fahn S. "On-off" phenomenon with levodopa therapy in parkinsonism: clinical and pharmacologic correlations and the effect of intramuscular pyrodoxine. Neurology 1974;24:431-41.

2 Wade DN, Mearrick PT, Burkett PJ et al. Variability of ê levodopa absorption in man. Aust NZ J Med 1974;4:138-43.

3 Pardridge W. Regulation of amino acid availability to the brain. In: Wurtman RJ, Wurtman JJ, eds. Nutrition and the brain. New York: Raven Press, 1977:141-204.

4 Wade LA, Katzman A. Synthetic amino acids and the nature of levodopa transport at the blood-brain barrier. J Neurochem 1975;25:837-42.

5 Mena I, Cotzias CG. Protein intake and the treatment of Parkinson's disease with levodopa. $N$ Engl J Med 1975;28:5-12.

6 Juncos JL, Fabbrini G, Mouradian MM, et al. Dietary influences on the antiparkinsonian response to levodopa. Arch Neurol 1987;44:1003-5.

7 Nutt JG, Woodward WA, Hammerstad JP, Carter JH, Anderson JL. The "on-off" phenomenon in Parkinson's disease: relation to levodopa absorption and transport. $N$ Engl J Med 1984;310:483-8.

8 Leenders KL, Poewe WH, Palmer AJ, et al. Inhibition of L-(18f) fluorodopa uptake into human brain by amino acids demonstrated by positron emission tomography. Ann Neurol 1986;20:258-61.

9 Kurlan A, Rubin AJ, Miller C et al. Duodenal delivery of levodopa for on-off fluctuations in parkinsonism: preliminary observations. Ann Neurol 1986;20:262-5.

10 Sage JI, Trooskin S, Heikkila R, Duvoisin RC. Long- 
term duodenal infusion of levodopa for on-off phenomena in parkinsonism: Continued good clinical response associated with gradually declining levodopa intake. Ann Neurol 1987;22:173.

11 Farrant M, Zia-Gharib F, Webster A. Automated precolumn derivatization with $\mathrm{O}$-phthalaldehyde for the determination of neurotransmitter amino acids using reverse-phase liquid chromatography. J Chromatogr 1987;417:385-90.

12 Wade DN, Mearrick PT, Morris JL. Active transport of levodopa in the intestine. Nature 1973;242:463-5.

13 Evans MA, Triggs EJ, Broe GA et al. Systemic availability of orally administered levodopa in the elderly patient. Eur J Clin Pharmacol 1980;17:215-21.
14 Eriksson T, Granerus A-K, Linde A, Carlsson A. "Onoff' phenomenon in Parkinson's disease: Relationship between levodopa and other large neutral amino acids in plasma. Neurology 1988;38:1245-8.

15 Pincus JH, Barry KM. Plasma levels of amino acids correlate with motor fluctuations in parkinsonism. Arch Neurol 1987;44:1006-9.

16 Wade LA, Katzman A. 3-O-methyldopa uptake and inhibition of levodopa at the blood-brain barrier. Life Sci 1975;17:131-6.

17 Sage JI, Trooskin S, Schuh I, et al. Isolated intestinal pouches for levodopa delivery in parkinsonian patients with on-off: Successful experimental model in dogs. Neurology 1987;37(Suppl 1):273. 